\title{
A FORÇA POLÍTICA DAS FAMÍLIAS TRADICIONAIS NO PARANÁ (1853-1889) ${ }^{1}$
}

\begin{abstract}
Alessandro Cavassin Alves ${ }^{2}$
- Enviado em 29/08/2015

- Aprovado em 15/09/2015

RESUMO

O presente artigo discute a política no Paraná no século XIX, a partir de sua emancipação em 1853 até o fim do Império brasileiro, em 1889, utilizando dos conceitos como classe política e a sua relação com a instituição familiar. Igualmente pensa esta mesma classe através da metodologia da prosopografia, privilegiando as características comuns destes atores. Com efeito, destaca-se um pequeno grupo, líderes de suas amplas famílias, que irão dominar e organizar a cena política paranaense.
\end{abstract}

Palavras-chave: Paraná. Classe política. Prosopografia.

\section{INTRODUÇÃO}

Este trabalho concentra sua área de investigação empírica e análise na formação de uma intrincada e visível rede familiar que ocupou as cadeiras de senador, deputado geral e deputado provincial do Paraná no período imperial, entre os anos de 1853 e 1889. Assim, busca-se entender este importante momento histórico do início da formação do "Paraná", através da análise de sua classe política $^{3}$, da qual eram membros e/ou herdeiros de uma classe senhorial colonial, isto é, de famílias que receberam sesmarias nesta região desde os séculos XVII ao XIX.

\footnotetext{
1 Tese defendida em 22/04/2014. Versão completa disponível na Biblioteca Digital da UFPR http://www.humanas.ufpr.br/portal/pgsocio/files/2014/05/R-T-Alessandro-Cavassin-Alves-2010-2014.pdf. Acesso em $26 / 08 / 2015$.

${ }^{2}$ Graduado em Ciências Sociais pela UFPR. Mestre em Sociologia pela UFPR. Doutor em Sociologia pela UFPR. Professor na FASBAM (Faculdade São Basílio Magno), UNIANDRADE e na Secretaria de Estado da Educação do Paraná (SEED). Endereço eletrônico: alessandrocavassin@gmail.com

${ }^{3}$ Para Gaetano Mosca a chamada classe política tinha como característica a organização e se destacava por possuir méritos e dons reconhecidos pela maioria governada, como força física, o contato direto com divindades, o saber, a riqueza, etc. E ainda, a existência de forças sociais que distinguem governantes de governados, como exemplo, o nascimento, a riqueza e o valor militar. Para Mosca, a classe política ao se estabilizar busca manter assim as posições
} 
Numa perspectiva genealógica este será um grupo político extremamente fechado e que assume, quase que naturalmente, o poder neste "novo território", povoado por aproximadamente sessenta mil almas cristãs no ano de 1853, e se perpetuando até o final do período imperial, quando o Paraná já contava com duzentos e cinquenta mil habitantes. Assumir o cargo público de senador, deputado geral ou provincial, ou mesmo de vereador e juiz de paz nas localidades, portanto, só era possível ao indivíduo que estava atrelado a uma estrutura familiar proprietária de terras e escravos, grande comerciante, empresário, por vezes com títulos acadêmicos, mas sempre com vínculos de nascimento ou casamento na região. Caso contrário, sem o apoio destas famílias, dificilmente um indivíduo conseguiria se eleger.

Este estudo justifica-se, também, porque são poucos, ainda, os pesquisadores que têm como foco o contexto específico do século XIX e, em especial, a ação política na província do Paraná4 Este contexto do poder local/provincial neste período é pouco explorado, bem como os temas que dele podem ser pesquisados, como a própria classe política, as leis aprovadas, os cargos ocupados, as obras públicas, as famílias, os partidos, as disputas internas por poder, a economia paranaense, a religião, enfim, campos de estudos que merecem ser aprofundados para uma melhor compreensão da história do Paraná.

\section{O CONTEXTO POLÍTICO BRASILEIRO NO SÉCULO XIX}

O Brasil, após sua independência política, em 07/09/1822, constituiu-se de um governo "monárquico hereditário, constitucional e representativo", dado por sua primeira Constituição,

alcançadas e garantir esta sucessão a seus descendentes. E argumentava que "qualquer indivíduo que faça parte da classe política deve ter, ou pelo menos presume-se que tenha, um mérito ou uma qualidade que não são possuídos por todos, aos quais, na sociedade em que vivemos, a maioria dos homens confere uma grande importância". E um destes méritos é o de ter nascido em uma família capaz de lhe proporcionar riqueza, educação, relações sociais, contatos, que dificilmente uma outra pessoa conseguiria (Mosca, 1925, in: GRYNSZPAN, 1999).

${ }^{4}$ Pode-se citar Cecília WESTPHALEN (1996) e David CARNEIRO (1994), com estudos específicos de política sobre o Paraná provincial; os manuais de história do Paraná, como o de Romário MARTINS (1995), BALHANA, MACHADO e WESTPHALEN, (Vol.1, 1969), Ruy WACHOWICZ (1982), Lucinéia STECA e Mariléia FLORES (2002), que de maneira ampla apresentam este momento; e, numa perspectiva geral sobre política nesta província, estudos como os de Temístocles LINHARES (2000), Marion MAGALHÃES (2001), Ricardo Costa de OLIVEIRA (2001), Amélia CORRÊA (2006), entre outros. 
outorgada pelo imperador D. Pedro I, em $25 / 03 / 1824^{5}$, de caráter centralizador, com um monarca considerado inviolável e sagrado, não podendo ser responsabilizado por seus atos e exercendo o poder moderador. Porém, se faz necessário analisar concretamente como este modelo institucional, com um poder moderador, se concretizava nas práticas políticas diárias, tanto nas províncias, como na Corte no Rio de Janeiro.

Mesmo sob este imperador soberano, por questões pessoais e conflitos internos no Brasil, D. Pedro I acabou abdicando do trono em 07/04/1831, em favor de seu filho, ainda criança. A Constituição previa, então, que o país fosse administrado por uma Regência, a qual, por sua vez, passou a discutir o arranjo institucional dado por sua Carta Magna; assim, alguns dos princípios constitucionais foram revistos sendo aprovado o Ato Adicional, de 12/08/1834 ${ }^{6}$, que reduziu a centralização política e administrativa no país, criando as assembleias legislativas provinciais, proporcionando, desta forma, maior autonomia às províncias e inserindo de maneira mais ativa as elites provinciais no processo decisório local; extinguiu também o Conselho de Estado, e transformou-se a Regência de trina em una, eleita pelo conjunto do país através do voto censitário, enquanto princípios mais próximos aos "liberais". Porém, a nação continuava a passar por duras instabilidades políticas, como a luta interna entre grupos, como os restauradores, moderados e exaltados, além das revoltas, como a Cabanagem, Balaiada, Sabinada e a Guerra dos Farrapos (CARVALHO, 2012). Diante disto, na década de 1840, antecipou-se a maioridade de D. Pedro II, em 23/07/1840, e políticos "conservadores" retomariam a organização do governo imperial aprovando leis interpretativas do Ato Adicional, com a volta do Conselho de Estado, em 23/11/1841, reformulando o Código de Processo Criminal, em 03/12/1841, e a Guarda Nacional. Mas, preservavam-se as assembleias legislativas provinciais. Enfim, havia a necessidade urgente e constante de organizar este imenso território.

No final da década de 1830 iniciava-se, assim, de maneira mais concreta, a formação dos dois únicos partidos políticos do Império: o liberal, que defendia as reformas do Ato Adicional de 1834; e o conservador, que buscava retomar princípios que proporcionasse ao governo central maior controle sobre as dissidências no Império. Entretanto, ambos os partidos passaram a auxiliar D. Pedro II a administrar o país ao longo de todo o segundo reinado, com a formação dos chamados gabinetes imperiais, porém, com o imperador mantendo a autonomia de nomear e destituir os

\footnotetext{
5 BRASIL, Constituição Política do Império do Brasil, 1824, in: http://www.planalto.gov.br/ccivil_03/constituicao/constitui\%C3\%A7ao24.htm. Acesso em 10/08/2013.

${ }^{6}$ BRASIL, Lei n. ${ }^{\circ}$ 16, de 12/08/1834, in: http://www2.camara.leg.br/legin/fed/lei/1824-1899/lei-16-12-agosto-1834532609-publicacaooriginal-14881-pl.html. Acesso em 10/08/2013. Conferir também: MONTEIRO, 1990, p.125-143.
} 
ministérios, e de convocar as assembleias legislativas gerais. Assim, conforme esclarece Fragoso \& Silva, é necessário atentar para os políticos do período imperial:

Isto é, a solução monárquica no Brasil, a manutenção da unidade da ex-colônia e a organização de um governo civil estável, resultam em grande medida do tipo de elite política presente à época da Independência, gerada, portanto, pela política colonial portuguesa. Essa elite se caracterizava pela homogeneidade, principalmente, no que se refere à ideologia e ao treinamento. É certo que existia também homogeneidade social entre seus membros, já que eles eram recrutados entre os setores sociais dominantes (proprietários de terras e comerciantes). Contudo, só isso não servia de garantia para a unidade da elite política, já que, como veremos, mesmo entre os grandes proprietários existiam conflitos de interesses, o que muitas vezes dificultava a ação coordenada. Nesse sentido, será a homogeneidade ideológica e de treinamento - padrões herdados da experiência colonial portuguesa - que reduzirá os conflitos intra-elite e possibilitará a implementação de um determinado modelo de dominação política (FRAGOSO \& SILVA, 1990, p.198).

A "solução monárquica no Brasil" passou, sem dúvidas, pela adesão de sua elite, neste trabalho considerado como uma classe política, que tinha um caráter homogêneo no que se refere à ideologia e ao treinamento (CARVALHO, 2003), mas dividida quanto a interesses específicos, por vezes locais e provinciais, o que, por vezes, acabou provocando conflitos sangrentos, como a Farroupilha, no Rio Grande do Sul, de 1835 a 1845; a revolta liberal de 1842, em São Paulo, Minas Gerais e Rio de Janeiro; e a insurreição praieira, em Pernambuco, em 1848 e 1849, na qual estavam envolvidos os interesses de classes dominantes. Reprimidas as revoltas, em 06/09/1853, formou-se o chamado gabinete da conciliação, em que conservadores e liberais estariam a governar de maneira conjunta, sob a liderança de Honório Hermeto Carneiro Leão, futuro Marques de Paraná, como forma de minimizar tais conflitos.

Enfim, sob este contexto político institucional, da década de 1850 foi que a região da comarca de Curitiba e Paranaguá, sul do Brasil, teve sua emancipação política aprovada em 29/08/1853, desmembrando-se de São Paulo, e com sua instalação em 19/12/1853 devido a chegada de seu primeiro administrador, o conservador Dr. Zacarias de Goes e Vasconcellos; região que recebeu a denominação "Paraná", título nobiliárquico do líder político da "conciliação"7.

\footnotetext{
${ }^{7}$ Sobre o processo de emancipação política da província do Paraná, conferir, entre outros estudos, os de Divonzir BELOTO (1990), Ricardo Costa de OLIVEIRA (2001) e Vítor Marcos GREGÓRIO (2012), na qual os autores discutem a criação, por parte do governo imperial, desta estratégica província ao sul do Brasil. Enfim, "o Paraná nasceu politicamente em sintonia com a ordem dominante central" (OLIVEIRA, 2001, p.xxi), no sentido de que a criação de uma província nesta região, entre São Paulo e o Rio Grande do Sul, seria um ponto de apoio à ordem legalista imperial. Seria igualmente a valorização da classe política local e a consolidação de sua adesão ao projeto político unitário do Império.
} 
Com isto, este território emancipado teve direito a eleger no ano seguinte um senador e um deputado geral, para representar a nova província na Câmara geral no Rio de Janeiro, e vinte deputados provinciais e seus suplentes. Enfim, os "paranaenses" tiveram de se articular para assumir o novo governo provincial; porém, coube aos grandes proprietários de terras e de gado, aos tropeiros, aos comerciantes, aos ervateiros e exportadores, residentes tanto no litoral como no planalto curitibano, enfim, os considerados homens bons desta parte do Império, o governo provincial, tendo a Assembleia legislativa provincial como o local privilegiado para assumir a direção político-institucional da nova província $^{8}$. Enfim, eram as famílias tradicionais a governar a nova província.

Compreender e caracterizar o movimento de consolidação desse grupo no poder, levantando de forma sistematizada quem foram os políticos eleitos na nova província brasileira, de maneira a identificar esta classe política paranaense e suas características neste período histórico específico, de 1853 a 1889, é uma metodologia fundamental na compreensão da política no Brasil.

Dessa forma, tendo em vista o caráter constante das eleições, mesmo que direcionadas pelos nomeados presidentes da província, mas que por sua vez ficavam pouco tempo na administração provincial, mesmo que manipuladas pelos líderes locais de acordo com o partido político dominante, é possível pensar a dinâmica política do Império dentro das províncias e a ação dos atores políticos locais, na figura dos líderes familiares e partidários, frente ao modelo centralizador de se conduzir a nação.

\section{QUESTÕES TEÓRICAS E METODOLPÓGICAS APLICADAS AO TRABALHO}

Justifica-se esta proposta de estudo e levantamento na medida em que se considera a instituição política denominada assembleia legislativa (tanto a provincial como a geral) e o senado como espaços nos quais os principais quadros políticos de uma região estão presentes, produzindo suas carreiras e relacionamentos nestes campos de poder (GOUVÊA, 2008; GOULART, 2008),

\footnotetext{
${ }^{8}$ Para Miriam DOLHNIKOFF (2005, p.284) as elites provinciais são um importante ator político na compreensão do Estado monárquico constitucional brasileiro no século XIX. A autora defende a tese da importância de se considerar as elites provinciais enquanto agentes fundamentais na construção do modelo de Estado unitário no Brasil, quando se buscou estabelecer um pacto federativo que respeitava e dava voz, através do parlamento, tanto provincial quanto o geral, a estas elites locais.
} 
discutindo seus projetos e consolidando seus interesses através do parlamento (DOLHNIKOFF, $2005)^{9}$, tendo como "limite" o poder moderador do Imperador, mas que governa em sintonia com estes interesses (ADORNO, 1988) ${ }^{10}$.

Para o desenvolvimento do trabalho, portanto, algumas fontes primárias privilegiadas do período em estudo são destacadas, visando à compreensão de quem seriam estes membros desta classe política paranaense; são elas as lista de votantes qualificados da província do Paraná a partir de 1854, que trazem dados como idade, estado civil, filiação, profissão e renda dos votantes; e a análise das eleições deste período; os partidos políticos, liberal e conservador, a qual cada um pertencia; os jornais de época ${ }^{11}$; destaca-se o jornal $O$ Dezenove de Dezembro, na qual estão publicados os atos do governo paranaense, bem como os diários da Assembleia legislativa provincial de boa parte do período, além dos resultados eleitorais e diversas outras informações sobre os políticos locais. Este jornal tem a característica de ser o único periódico que foi publicado de 1854 a 1890, praticamente sem interrupções, e preservado integralmente no Museu Paranaense, instituição que foi inaugurada em 25/09/1876; além de outros periódicos, do Paraná e do Império, disponíveis, em especial, na hemeroteca digital brasileira, da Fundação Biblioteca Nacional ${ }^{12}$; os discursos de abertura e encerramento da Assembleia legislativa, o primeiro pelo presidente da província e o último pelo presidente da Assembleia; a Genealogia paranaense, em especial a obra de Francisco Negrão em seis volumes ${ }^{13}$; a legislação eleitoral deste período; e as leis e decretos da

\footnotetext{
${ }^{9}$ Para Miriam DOLHNIKOFF (2005, p.17-18), "na Câmara [geral, pós 1834] as elites encontraram o espaço de defesa de seus interesses, negociando demandas que se confrontavam tanto entre as diversas províncias como entre estas e o centro. Neste modelo, a divisão territorial em províncias correspondeu à existência de governos autônomos em relação a matérias de grande importância, sobre as quais esses governos atuavam unilateralmente, com poderes irrevogáveis pelo governo central".
}

${ }^{10}$ Para Sérgio ADORNO (1988, p.62) os diversos grupos de proprietários rurais, uma vez garantido a ordem no interior de suas grandes unidades produtoras, tratavam de exercer controle sobre o "aparelho do Estado a fim de assegurar a livre circulação da riqueza produzida. Foi precisamente nesse plano que a existência do poder moderador impediu a concretização da hegemonia política dos grandes proprietários rurais. Assim, se esses grupos sociais foram dominantes relativamente aos grupos sociais antagônicos, não foram em igual medida dirigentes com referência aos grupos sociais afins".

11 Romário MARTINS (1908) apresenta a lista de jornais publicados no Paraná de 1854 a 1907 . Durante o período imperial foram publicados em Curitiba aproximadamente 80 periódicos, além de periódicos publicados no litoral do Paraná e Campos Gerais. Destacam-se neste trabalho O Dezenove de Dezembro (1854/1890); Correio Official (1862/63); Província do Paraná (1876 - Estado do Paraná, 1889), Gazeta Paranaense (1876); A República (1886).

${ }^{12}$ Disponível em: http://memoria.bn.br/hdb/periodico.aspx.

${ }^{13}$ A Genealogia Paranaense, obra de Francisco Negrão, em seis volumes é uma fonte muito rica quando se quer saber as relações de parentesco na história paranaense, anterior ao início do século XX. "O autor seguiu tradicionais procedimentos investigativos no campo genealógico, constituindo-se em fundamental recurso para aqueles que desejam conhecer e pesquisar a formação da classe dominante real do Paraná enquanto uma totalidade histórica concreta e viva. Certamente que um instrumento como a genealogia deve ser rigorosamente verificado e considerado no seu método e na sua exatidão a partir de outras fontes" (OLIVEIRA, 2001, p.33, nota 17). Portanto, apesar de ser uma fonte privilegiada 
província do Paraná. Essas fontes, em seu conjunto, permitem ao pesquisador relacionar dados formando uma compreensão mais ampla de quem eram os indivíduos eleitos no Paraná.

A metodologia privilegiada é a biografia coletiva ou prosopografia dos políticos paranaenses no período imperial (1853 a 1889) ${ }^{14}$. Isto possibilita demonstrar uma visão conjunta destes políticos, enquanto representantes eleitos, sob as regras institucionais do regime monárquico constitucional e sob os costumes da época. O ganho neste tipo de estudo, sobre quem é quem, trajetórias individuais e de grupos, enriquecem a compreensão da constituição dos fenômenos sociais e políticos, afinal, busca-se conhecer "o que de real existe no papel das elites" (CARVALHO, 2003, p.20). Ao todo são 188 indivíduos que assumiram os cargos de deputado provincial, geral e senador ao longo do período de 1853 a 1889 no Paraná ${ }^{15}$.

Com a leitura dos jornais de época e demais documentos é possível reconstruir uma crônica política $^{16}$ deste período, com o objetivo de se observar a classe política desta província, e em ordem cronológica, isto é, dos deputados provinciais eleitos desde a $1^{\mathrm{a}}$ legislatura em 1854 e 1855 até a $18^{\mathrm{a}}$ legislatura em 1888 e 1889, sendo esta a última do período imperial. Isto, também, observando quem foram os personagens eleitos respectivamente para senador e deputado geral, as nomeações e posses dos presidentes e vice-presidentes da província, por vezes seus secretários e demais autoridades nomeadas para os municípios, assim, também, acompanhando a eleição de vereadores e juízes de paz das vilas paranaenses, e de eleitores; e tudo isso com o cuidado metodológico de não se tomar como verdade única ou absoluta os fatos relatados pelos jornais, ou seja, na medida do possível buscam-se contrapontos em outras fontes, construindo aqui um conhecimento crítico e reflexivo. Assim, no desenvolvimento desta crônica política, propõe-se encontrar as características gerais desta classe política a governar, através da metodologia da prosopografia. Estes fatos políticos retomados terão como objetivo demonstrar que estes atores políticos envolvidos, membros de tradicionais famílias paranaenses, estão realmente, e em todo este extenso momento histórico, a controlar e/ou a lutar pelo poder nesta província.

neste estudo, buscam-se apontar seus limites, nomes omitidos, famílias não citadas, problematizam-se, igualmente, as escolhas feitas pelo próprio Francisco Negrão enquanto membro das tradicionais famílias paranaenses.

14 Conferir, entre outros, STONE (2011); BARMAN \& BARMAN (1976); BURKE (1991); OLIVEIRA (2001); CARVALHO (2003); CORRÊA (2006); HEINZ (2006); LOVE (2006).

\footnotetext{
${ }^{15}$ No trabalho de tese está disponível a ficha biográfica de todos estes políticos paranaenses na qual se busca ressaltar os aspectos familiares e de parentesco (avôs, pais, casamentos, compadrios), residência, educação e profissão, cargos públicos (enquanto trajetória) e títulos nobiliárquicos. Cf. http://www.humanas.ufpr.br/portal/pgsocio/files/2014/05/RT-Alessandro-Cavassin-Alves-2010-2014.pdf. Acesso em 26/08/2015.

16 A esta retomada dos fatos políticos chamar-se-á "crônica política", enquanto uma tentativa de reescrita dos acontecimentos registrados nos jornais paranaenses e do Brasil do século XIX.
} 
Porém, sabe-se que a simples construção de trajetória destes indivíduos, "como uma série de posições sucessivamente ocupadas por um mesmo agente (ou um mesmo grupo), em um espaço ele próprio em devir e submetido a transformações incessantes", como demonstra Pierre Bourdieu (1996, p.81-82), leva a uma "ilusão biográfica", prejudicial à compreensão dos fenômenos sociais.

Tentar compreender uma vida como uma série única e, por si só, suficiente de acontecimentos sucessivos, sem outra ligação que a vinculação a um "sujeito" cuja única constância é a do nome próprio, é quase tão absurdo quanto tentar explicar um trajeto no metrô sem levar em conta a estrutura da rede, isto é, a matriz das relações objetivas entre as diversas estações (BOURDIEU, 1996, p.81).

As fichas biográficas destes indivíduos que ocupam as posições de governo, por si só, nada explicariam, e as posições que vão ocupando ao longo da vida, destacadas neste trabalho, não significam a existência de um todo coerente, coeso e atado por uma cadeia de inter-relações. Esta é dada, a posteriori, pelo indivíduo ou pesquisador (MONTAGNER, 2007, p.252).

Portanto, é necessário considerar que:

Os acontecimentos biográficos definem-se antes como alocações e como deslocamentos no espaço social, isto é, mais precisamente, nos diferentes estados sucessivos da estrutura da distribuição dos diferentes tipos de capital que estão em jogo no campo considerado. É evidente que o sentido dos movimentos que levam de uma posição a outra (...) define-se na relação objetiva entre o sentido dessas posições no momento considerado, no interior de um espaço orientado. Isto é, não podemos compreender uma trajetória (...), a menos que tenhamos previamente construído os estados sucessivos do campo no qual ela se desenrolou; logo, o conjunto de relações objetivas que vincularam o agente considerado (...) ao conjunto dos outros agentes envolvidos no mesmo campo e que se defrontam no mesmo espaço de possíveis (BOURDIEU, 1996, p.81-82).

É necessário situar os agentes sociais em seu grupo social, nos campos na qual transitam, e das possibilidades existentes neste meio, e os capitais específicos que estes indivíduos ou grupos possuem. E frente ao contexto histórico, a saber, levando-se em consideração as instabilidades constantes da troca de gabinetes do Império, entre liberais e conservadores, as mudanças na legislação eleitoral e a discussão sobre temas como o fim da escravidão, o que se concluirá é que uma estabilidade "institucional" atravessará todo este período, tendo sempre a frente os mesmos indivíduos no poder ${ }^{17}$.

17 José Honório RODRIGUES (1981, p.10) defende a tese de que "a realidade brasileira contém, historicamente falando, elementos arcaicos, coloniais (absolutismo, patriarcalismo, paternalismo, autoritarismo, latifúndio), 
Outro ponto a destacar é que os documentos de época, em especial seus periódicos, da qual a crônica política é produzida, revela apenas o lado dominante, oficial, de uma classe senhorial que vai ocupando a instituição estatal, e ao mesmo tempo passam a escrever os acontecimentos que mais lhes interessam. "A outra história" que se passa "na área popular", como se refere José Honório Rodrigues (1981, p.13) é a de um povo "mudo", por vezes "sangrado e capado", em que é difícil conhecer ou reconstruir suas aspirações e angústias. Este é o caso, por exemplo, dos imigrantes no Paraná, chegados a partir do século XIX, que apesar de muitos, como os alemães em Curitiba, apenas lentamente foram ouvidos e consequentemente incorporados a esta classe senhorial.

\section{UM CONCEITO FUNDAMENTAL: A INSTITUIÇÃO FAMÍLIA}

Uma instituição que se deve analisar é a família, como "elemento poderoso de unificação" da classe política paranaense ${ }^{18}$. Oliveira Vianna descreve este complexo de família senhorial, como uma instituição que ao longo dos séculos foi se moldando, desde a particularidade de isolamento e de elemento de defesa contra o ataque dos índios e mesmo de senhor contra senhor, isto por motivos de sobrevivência, de disputas de terras, limites de sesmarias, de roubo de gado e escravos, enfim, armavam-se em suas fazendas verdadeiras fortalezas (VIANNA, 1949, p.207-236) ${ }^{19}$. Esta seria a grande estrutura da família senhorial que foi se consolidando, reforçando os laços de solidariedade e submissão entre seus membros, com reflexos em toda a organização social e política brasileira.

sobrevivências imperiais (falsidade da vida política representativa, organização econômica dirigida para o exterior, e enquadrada numa estrutura internacional que a subjuga, predomínio de preconceitos e privilégios, conciliação, divórcio entre Poder e Sociedade) e vivências atuais (marchas e contramarchas, reformismo e anti-reformismo, com predominância deste, proscrição e acolhida dos trabalhadores, estudantes e jovens, etc., e não-ruptura das estruturas arcaicas nacionais e internacionais que constituem obstáculos ao crescimento). Daí resulta, na realidade presente, a estabilidade da estrutura e a instabilidade da conjuntura; a sobrevivência do arcaico e a derrota do contemporâneo". Conferir também, José Honório RODRIGUES (1965) sobre o conceito da "conciliação" como prática política.

18 José Murilo de CARVALHO (2003, p.138) discute os "elementos poderosos de unificação" da elite imperial no século XIX, na qual destacou "educação", "ocupação" e "carreira", que propiciaram que "tanto liberais como conservadores, nos períodos turbulentos de consolidação do poder, quando várias alternativas se colocavam como viáveis politicamente, concordavam em alguns pontos básicos referentes à manutenção da unidade do país, à condenação de governos militares caudilhesco ou absolutista, à defesa do sistema representativo, à manutenção da monarquia e, sem dúvida, também à necessidade de preservar a escravidão". Este trabalho acrescentaria o item família como "elemento poderoso de unificação" desta classe política.

${ }^{19}$ Oliveira Vianna denomina este início de clã feudal, conceito, porém, que se considera não pertinente a esta realidade brasileira, devido as características destas fazendas fortalezas, que apesar de isoladas, possuíam claras e constantes ligações com as vilas e o litoral brasileiro. 
Neste sentido, Oliveira Vianna também demonstra o surgimento de um clã parental, que organiza a solidariedade social desta classe rural:

O clã parental é uma organização aristocrática. É uma espécie de Ordem da Cavalaria das grandes famílias dominiciais. Foi enorme a sua influência no Período Colonial e, ainda maior, no Período Imperial e na República (VIANNA, 1949, p.233).

O clã parental incluiria, então, o patriarca da família, os parentes consanguíneos (filhos e netos), os parentes colaterais (irmãos, tios e sobrinhos), os parentes por afinidade civil (genros e cunhados), os parentes por afinidade religiosa (os "compadres" e "afilhados"), e os parentes por adoção (os "crias" da casa senhorial e, sem dúvida, os "moleques mimosos", de Antonil e de Vilhena) (VIANNA, 1949, p.242). Entre eles, há o que Oliveira Vianna chama de solidariedade parental, que de certa forma os identifica, como quando acontecem lutas de famílias ou ainda prélios eleitorais, decorrentes do novo regime democrático, pós 1824.

Este campo familiar, para o caso brasileiro, ajuda a traçar este primeiro momento das relações de influência, subordinação, dominação dentro da distribuição estrutural da classe dirigente (MONTAGNER, 2007, p.254). As posteriores lutas para se ocupar as posições de mando, como exemplo, nas vilas, províncias e mesmo na corte, terão como base a estrutura familiar. E, para Oliveira Vianna, como consequência, surge a necessidade da formação do clã eleitoral, uma junção de aristocratas que passariam a se impor nas disputas eleitorais. Disputas, porque grupos iam se formando, e que acabavam convergindo para os dois únicos partidos políticos do Império, o liberal e o conservador.

O clã eleitoral é uma nova fase dos clãs rurais, que exige a liderança de um chefe ostensivo, que promova entre seus pares a solidariedade e a cooperação, mesmo que através do poder da força, frente a outros inimigos, outros chefes que venham a surgir ou tão poderosos quanto.

\footnotetext{
"Este chefe ostensivo é um agente unificador local: é o garante da unidade do comportamento dos clãs agremiados num destes dois grupos sociais [liberais ou conservadores], não existentes anteriormente" (VIANNA, 1949, p.279).
}

São clãs de bases municipais, com o objetivo de controlar os postos de autoridades locais. Clãs que se ligavam aos presidentes nomeados da província, que vinham em nome do gabinete imperial e do partido político que os nomeava. Nomeações a nível municipal e nomeações em nível de província eram, então, delegadas pelo presidente nomeado, como a guarda nacional. 
Era esta justamente a função política da Guarda Nacional: permitir ao senhor mais rico ou mais poderoso (pela proteção que lhe dispensava o Governador, concedendo-lhe o recrutamento, a polícia civil e militar, a câmara municipal com os seus almotacéis) imporse aos demais clãs feudais e senhoriais pelo princípio da disciplina e obediência militar e também por esse aliciamento espontâneo, que o comando militarizado naturalmente suscita (VIANNA, 1949, p.285).

Portanto, a solidariedade e coesão do clã parental, por vezes, será marcada pela divisão em partidos políticos, ou mesmo dentro de um mesmo partido, verificam-se dissensões, mas nada que afete a estrutura de ocupação da posse destes cargos. Para Oliveira Vianna, as divisões partidárias não seriam significativas na compreensão da política no Império.

É possível identificar no Paraná do século XIX, estes "chefes ostensivos" de grande parentela, proprietários rurais ou negociantes, ervateiros, senhores de escravarias, chefes do partido local, que dominam os cargos públicos municipais e provinciais, nomeando seus parentes e correligionários, formando as chapas para concorrem às eleições, aliciando novos genros, e que vão se impondo na condução dos destinos de suas localidades e da nova província brasileira, e alguns adentrando no restrito círculo do poder na Corte, no Rio de Janeiro. E o "bastão" do poder nas localidades só era trocado quando da mudança do gabinete imperial, no Rio de Janeiro, uma mudança de conservador para liberal e vice-versa.

Utilizando-se das referências de Pierre Bourdieu, as trajetórias destes agentes políticos estão ligadas ao enquadramento de campo, que é a família, devido à proximidade de parentesco entre eles.

Maria Fernandes Martins (2007), para o caso brasileiro, faz uma análise mais ampla do comportamento destas famílias nacionais. A autora apresenta, então, 42 nomes de dirigentes imperiais que provêm das redes familiares das províncias "mais dinâmicas do país", como exemplo, da família Cavalcanti de Albuquerque de Pernambuco, tem-se Pedro de Araujo Lima, marquês de Olinda, que teria participado dos Conselhos de Estado e de inúmeros gabinetes ministeriais. Assim como, Honório Hermeto Carneiro de Leão, o marquês de Paraná, da família Carneiro Leão de Minas Gerais e Rio de Janeiro. José Bonifácio Ribeiro de Andrada, da família Ribeiro de Andrada de São Paulo. Enfim, ao longo de todo o período imperial, independente das mudanças ocorridas, eles estarão nos postos de comando da nação. E ainda, todos são provenientes de redes familiares já presentes no Brasil que ocupavam os cargos e atividades de destaque desde os séculos XVII e XVIII (MARTINS, 2007, p.415-420). 
Estas famílias vão se apropriando do aparelho do Estado, conforme esclarece Mattos:

\begin{abstract}
Intimamente ligados ao aparelho de Estado, expandiam seus interesses, procuravam exercitar uma direção e impunham uma dominação. No momento em que se propunham a tarefa de construção de um Estado soberano, levavam a cabo o seu próprio forjar enquanto classe, transbordando da organização e direção da atividade econômica meramente para a organização e direção de toda a sociedade, gerando o conjunto de elementos indispensáveis à sua ação de classe dirigente e dominante. Não se constituindo unicamente dos plantadores escravistas, mas também dos comerciantes que lhes viabilizavam e, por vezes, com eles se confundiam de maneira indiscernível, além dos setores burocráticos que tornavam possíveis as necessárias articulações entre política e negócios, a classe senhorial se distinguiria nesta trajetória por apresentar o processo no qual se forjava por meio do processo de construção do Estado Imperial (MATTOS, 1990, p.57).
\end{abstract}

Neste sentido, é interessante analisar, em pleno século XIX, que esta classe senhorial ia estruturando seus novos membros através de "política matrimonial”, genrocracia ${ }^{20}$ ou cunhadismo, que segundo Darcy Ribeiro seria uma herança indígena utilizada desde o início da colonização e povoamento destas terras, prática que, sem ela, seria "impossível a criação do Brasil":

A instituição social que possibilitou a formação do povo brasileiro foi o cunhadismo, velho uso indígena de incorporar estranhos à sua comunidade. Consistia em lhes dar uma moça índia como esposa. Assim que ele a assumisse, estabelecia, automaticamente, mil laços que o aparentavam com todos os membros do grupo (RIBEIRO, 1997, p.81).

Enfim, um "sistema de parentesco classificatório dos índios, que relaciona, uns com os outros, todos os membros de um povo" (idem). Darcy Ribeiro destaca, então, para o Brasil como um todo, exemplos de portugueses que ao contraírem laços com as índias locais, consolidaram longas parentelas. João Ramalho e seu companheiro Antonio Rodrigues, formando os núcleos paulistas, Diogo Álvares, Caramuru, pai heráldico dos baianos, Jerônimo de Albuquerque em Pernambuco e Maranhão. Mesmo os franceses e espanhóis "participaram da fase cunhadística da

\footnotetext{
${ }^{20}$ Muitos autores buscam compreender estes laços familiares no Brasil. Gilberto Freyre utiliza do termo genrocracia, prática em que fazendeiros procuravam bacharéis promissores, por vezes de fortuna modesta, para casarem suas filhas. José Murilo de Carvalho aproveita deste termo para apresentar a trajetória de Paulino José Soares de Sousa, o Visconde do Uruguai no Brasil Império, e as relações familiares envolvidas em sua carreira; o jovem promissor Paulino, recém formado em Direito, casa-se com Ana Maria Macedo Álvares de Azevedo, filha de importante fazendeiro em Itaboraí. O casamento ocorreu na casa de seu concunhado Joaquim José Rodrigues Torres, o Visconde de Itaboraí, que junto com Eusébio de Queiroz formariam a famosa trindade saquarema. José Murilo de Carvalho diz que "nem os Soares de Sousa nem os Torres, comerciantes e fazendeiros de Itaboraí, tinham grande peso econômico e social. Mas a aliança com famílias mais importantes envolveu Paulino e Rodrigues Torres numa intrincada rede de relações que abrangia partes do Rio de Janeiro, do Espírito Santo e Minas Gerais" (Carvalho, in: URUGUAI, 2002, p.14-16).
} 
implantação europeia na costa brasileira" (Ibidem, p.86) ${ }^{21}$. Com a influência jesuítica, da estrutura administrativa do império português no Brasil, do sistema de escravidão, novos elementos foram se consolidando na formação do povo brasileiro. Mas, o cunhadismo estará presente em pleno século XIX, enquanto “instituição social”, como forma agregadora de um clã parental.

No Paraná, como exemplo, em 1854, na primeira eleição para senador, deputado geral e deputados provinciais da nova província, num total de vinte e oito indivíduos eleitos, apenas um não teria uma ligação de parentesco direta com os seus pares neste momento específico, por ser recém chegado do Rio de Janeiro com cargo público nomeado pelo Imperador. Era, literalmente, a parentela eleita para governar.

Seria por meio dos casamentos, contudo, que se estabeleceriam sólidas e frutuosas relações entre as grandes famílias, preocupadas em preservar os monopólios que as distinguiam, e os elementos que as representavam, e a quem caberia ordenar esses mesmos monopólios, como tantas vezes já assinalamos. Tal forma de forjar uma relação fundamental para a constituição de uma classe, não deixava de por em relevo a figura da mulher, precioso capital de que lançavam mão pais monopolizadores e que, de modo irônico, contribuía para a acumulação de poder pelo Estado em consolidação (MATTOS, 1990, p.188).

Seria, portanto, a família um conceito fundamental para entender o Brasil no século XIX? Pierre Bourdieu (1996, p.126-135), em busca da gênesis dos conceitos, comenta que família é uma palavra de ordem, uma categoria, princípio coletivo de construção da realidade coletiva, uma ficção bem fundamentada, que contribui "para reproduzir a categoria social objetiva" num "círculo de reprodução da ordem social". Igualmente, produto de um "verdadeiro trabalho de instituição" que visa assegurar sentimentos de integração "que é condição de existência e de persistência dessa unidade”, impondo "nome de família", “casamento" etc.

As estruturas de parentesco e a família como corpo só podem se perpetuar ao preço de uma criação continuada do sentimento familiar, princípio cognitivo de visão e de divisão que é, ao mesmo tempo, princípio afetivo de coesão, isto é, adesão vital à existência de um grupo familiar e de seus interesses.

\footnotetext{
${ }^{21}$ José Honório RODRIGUES (1965, p.27) discute, entretanto, estes tipos de povoadores, que apesar deste processo de assimilação parental, uma maioria era obrigada a sujeitar-se a uma cultura formal e processual, legal e política, de caráter ocidental europeu, imposta pela minoria, que fabricava, "substancialmente, da contradição entre a tese portuguesa e a antítese da natureza, dos índios, negros e mestiços, uma síntese nova e original”. Mas, destaca o historiador, "não são só os vencedores que determinam o conteúdo do processo histórico, e apesar do europeísmo e lusitanismo vitorioso e dominante na aparência das formas sociais, o substrato era novo, era o Brasil que nascia". Isto construído entre episódios denominados de história cruenta e incruenta quando necessário ("terrorismo-amansamento"), da conciliação entre primos ricos e pobres, sem alterar, assim, os privilégios conquistados, o status quo obtido pela minoria, na imensidão das novas terras, brasileiras.
} 
Esse trabalho de integração é tanto mais indispensável porque a família, que para existir e subsistir deve se afirmar como corpo, sempre tende a funcionar como um campo, com suas relações de força física, econômica e, sobretudo simbólica (vinculadas, por exemplo, ao volume e à estrutura dos capitais que seus diferentes membros possuem) e suas lutas pela conservação ou transformação dessas relações de força. (BOURDIEU, 1996, p.130).

Portanto, o sentimento familiar será reforçado de acordo com a importância que seus membros dão em perpetuarem determinados interesses, formando um campo numa dinâmica que os leva a conservação ou mesmo transformação de suas características. Numa estrutura em que o capital econômico prevalece, a família, enquanto corpo com sentimentos recíprocos de proteção os levaria a perpetuar, ou mesmo ampliar as conquistas já adquiridas, protegendo os seus próprios membros. A família acaba tendo a característica de um lugar da reprodução social. Como exemplo, na transmissão do nome de família, elemento primordial do capital simbólico hereditário, o pai transfere aos filhos uma "herança" social construída a partir de outros capitais conquistados por esta família. No século XIX, denominar alguém de "Junior", "Filho", "Sobrinho", "Neto" conferia a esta pessoa destaque social ${ }^{22}$.

Uma das particularidades dos dominantes é a de possuírem famílias extensas (os grandes têm famílias grandes) e fortemente integradas, já que unidas não apenas pela afinidade dos habitus, mas também pela solidariedade dos interesses, isto é, tanto pelo capital quanto para o capital, o capital econômico, evidentemente, mas também o capital simbólico (o nome) e sobretudo, talvez, o capital social (que sabemos ser a condição e o efeito de uma gestão bemsucedida do capital coletivo dos membros da unidade doméstica) (BOURDIEU, 1996, p.132133).

Pierre Bourdieu percebe na família uma estrutura de relações de força entre os membros de seu grupo funcionando como campo, que os distingue e os protege, pela "solidariedade dos interesses”. No Paraná, século XIX, observando os membros eleitos para os cargos de decisão política do Estado, poderá se dizer que esta concepção de família ligada por interesses conjuntos de proteção e comando será bastante forte.

\footnotetext{
${ }^{22}$ Como exemplo no Paraná, o importante político Joaquim Ignácio Silveira da Mota Junior, terá um filho com o mesmo nome, e ele que é filho do médico Joaquim Ignácio Silveira da Mota e neto de Joaquim Ignácio Silveira da Mota. Como tio tinha o deputado provincial por São Paulo e depois senador por Goiás, Dr. José Ignácio Silveira da Mota, que ficou no cargo vitalício de 1855 a 1889. Entre muitos outros exemplos. O historiador Georgy Duby (1989; 2011) faz inúmeros estudos da importância dos vínculos de parentescos na sociedade chamada feudal. Ao analisar a genealogia de muitas famílias aristocráticas francesas, e suas relações com a estrutura do Estado, acaba observando que o indivíduo descendente de antigas famílias, "ele se sente membro de uma linhagem, de uma raça na qual, de pai para filho, transmite-se uma herança, membro de uma 'casa' cuja direção se transmite para o mais velho dentre os filhos e cuja história pode se escrever, sob a forma de uma árvore enraizada na pessoa do ancestral fundador, a origem de todo o poder e de todo o prestígio da estirpe. $\mathrm{O}$ indivíduo se tornou ele próprio um príncipe; ele adquiriu uma consciência de herdeiro" (DUBY, 2011, p.134).
} 
Apesar desta constatação, não se está querendo caracterizar a sociedade brasileira pela imobilidade social e política, com a permanência dessas redes familiares sem mudanças, afinal também estas famílias no poder estão buscando caminhos de manutenção dos privilégios adquiridos, reagindo a conjunturas desfavoráveis, formando novas alianças, incorporando novos membros, e outras ainda desaparecendo. Desta forma, entendem-se as lutas políticas partidárias, os desentendimentos entre membros do próprio partido, familiares que estão em partidos distintos, agremiações partidárias surgindo, por vezes sem nenhuma ligação à classe política tradicional. Mas ao mesmo tempo, esta estrutura familiar foi bastante forte, portanto, ainda capaz de contribuir nas explicações sobre a política brasileira atual.

\section{CONSIDERAÇÕES FINAIS}

O tema da política no Paraná, no século XIX, focando a Assembleia Legislativa e sua classe política permite perceber quem são seus principais atores, com a função de legislar sobre diversos assuntos relativos ao desenvolvimento da região paranaense.

Quanto aos deputados provinciais, estes eram eleitos para mandatos de dois anos, e se reuniam em Curitiba, num período de dois meses, com reuniões diárias. Os deputados eleitos eram provenientes de Curitiba e municípios vizinhos, do litoral, dos Campos Gerais e de Guarapuava. A tese deste trabalho busca demonstrar que estes deputados provinham todos das tradicionais famílias "paranaenses", herdeiras de sesmarias recebidas nesta região desde o século XVII, mas que além da posse de terras, elas tinham grande capital econômico. Eram tropeiros, fazendeiros, ervateiros, comerciantes e, ao longo do tempo, com formação educacional - formados em direito, medicina, engenharia e humanidades, e com formação eclesiástica, e com fortes laços de matrimônio entre eles. E sempre estas famílias tinham importantes cargos públicos no Estado. E eram liderados por alguns dos mais proeminentes políticos do Paraná e do Império.

Eram eles: Manoel Francisco Correia, funcionário imperial, formado em direito, deputado provincial e geral, presidente de província e depois senador pelo Paraná; Manoel Eufrásio Correia, funcionário imperial, formado em direito, deputado provincial e geral e presidente de província; Manoel Antonio Guimarães, Visconde de Nácar, negociante e empresário em Paranaguá, deputado provincial e geral, vice-presidente de província, casado com Maria Clara Correia, irmã de Manoel 
Eufrásio Correia - que em segundas núpcias casa com a sua sobrinha, filha do Visconde de Nácar; Agostinho Ermelino de Leão, baiano, formado em direito, desembargador, vice-presidente da província, casado com Maria Bárbara Correia, irmã do senador Correia; e Ildefonso Pereira Correia, barão de Serro Azul, empresário, ervateiro, vereador, deputado provincial, irmão do senador Correia. Era a grande família Correia Guimarães Leão, ligada ao partido conservador.

Outra família tradicional era a do Dr. Jesuino Marcondes de Oliveira e Sá, filho do Barão de Tibagi, formado em Direito, vereador, deputado provincial e geral, ministro da agricultura, presidente de província, casado com Domitila Alves de Araújo, irmã do comendador Antonio Alves de Araujo, empresário, deputado provincial, vice-presidente de província, e seu irmão comendador Manoel Alves de Araujo, formado em Direito, deputado provincial e geral, ministro da agricultura, oriundos de Antonina, litoral do Paraná, e casados com mulheres das famílias tropeiras, como a família do barão dos Campos Gerais, David dos Santos Pacheco, da Lapa; Generoso Marques dos Santos, curitibano, formado em Direito, deputado provincial e geral; José Lourenço de Sá Ribas, curitibano, da grande família Sá Ribas, formado em Direito, deputado provincial. Estes últimos formavam outra grande estrutura familiar, ligada ao partido liberal.

Estes homens e suas grandes famílias dominaram a política paranaense, bem como os interesses e as políticas deste estado, durante o período de 1853 a 1889 e com ampla representatividade no governo imperial, junto ao imperador D. Pedro II.

\section{REFERÊNCIAS BIBLIOGRÁFIAS}

ADORNO, Sérgio. Os aprendizes do poder. Rio de Janeiro: Paz e Terra, 1988.

ALVES, Alessandro Cavassin. A Província do Paraná (1853-1889). A Classe Política. A Parentela no Governo. Tese doutorado em Sociologia. Curitiba: UFPR, 2014. Disponível em: http://www.humanas.ufpr.br/portal/pgsocio/files/2014/05/R-T-Alessandro-Cavassin-Alves-20102014.pdf. Acesso em 26/08/2015.

BALHANA, A.P.; MACHADO, B.P.; WESTPHALEN, C.M. História do Paraná. Vol.1. Curitiba: Grafipar, 1969. 
BARMAN, R.; BARMAN, J. The Role of the Law Graduate in the Political Elite of Imperial Brazil. Journal of Interamerican Studies and World Affairs, v. 18, n. 4, p. 423-450, 1976.

BELOTO, Divonzir Lopes. A criação da província do Paraná: a emancipação conservadora. São Paulo: PUC SP, dissertação em Economia, 1990.

BOURDIEU, Pierre. Razões práticas: Sobre a teoria da ação. Campinas, SP: Papirus, 1996.

BRASIL, Constituição Política do Império do Brasil, 1824, in: http://www.planalto.gov.br/ccivil_03/constituicao/constitui\%C3\%A7ao24.htm. Acesso em 10/08/2013.

BRASIL, Lei n. ${ }^{\circ}$ 16, de 12/08/1834, in: http://www2.camara.leg.br/legin/fed/lei/1824-1899/lei-1612-agosto-1834-532609-publicacaooriginal-14881-pl.html. Acesso em 10/08/2013.

BURKE, Peter. Veneza e Amsterdã. Um estudo das Elites do século XVII. São Paulo: Ed. Brasiliense S.A., 1991.

CARnEIRO, David. História do Período Provincial do Paraná. Galeria de Presidentes da Província. Curitiba: Banestado, 1994.

CARVAlHO, José Murilo de. A construção da ordem: a elite política imperial. Teatro das sombras: a política imperial. Rio de Janeiro: Civilização Brasileira, 2003.

CARVALHO, José Murilo de (Org.). A construção nacional, 1830-1889. vol.2, Rio de Janeiro: Objetiva, 2012.

CORRÊA, Amélia Siegel. Imprensa e Política no Paraná: Prosopografia dos redatores e pensamento republicano no final do século XIX. Dissertação Sociologia, Curitiba, UFPR, 2006.

DOLHNIKOFF, Miriam. O pacto imperial. Origens do federalismo no Brasil. São Paulo: Globo, 2005.

DUBY, Georges. Linhagem, nobreza e cavalaria no século XII na região do Mâconnais - uma revisão. A sociedade cavaleiresca. São Paulo: Martins Fontes, 1989. 
Idade Média. Idade dos Homens. São Paulo: Companhia das Letras, 2011.

FRAGOSO, João Luís; SILVA, Francisco Carlos Teixeira da. Parte B: A Política no Império e no Início da República Velha: dos barões aos coronéis. In: LINHARES, Maria Yeda (org.). História geral do Brasil. 6ed. Rio de Janeiro: Campus, 1990.

GOUlART, Mônica Helena Harrich Silva. Classe dominante e jogo político na Assembleia Legislativa Paranaense (1889-1930). Tese de Doutorado em Sociologia, Curitiba, UFPR, 2008.

GOUVÊA, Maria de Fátima Silva. O império das províncias. Rio de Janeiro, 1822-1889. Rio de Janeiro: Civilização Brasileira, 2008.

GREGORIO, Vitor Marcos. Dividindo as províncias do império: a emancipação do Amazonas e do Paraná e o sistema representativo na construção do Estado nacional brasileiro (1826-1854). 2012. Tese (Doutorado em História Econômica) - Faculdade de Filosofia, Letras e Ciências Humanas, Universidade de São Paulo, São Paulo, 2013. Disponível em: http://www.teses.usp.br/teses/disponiveis/8/8137/tde-12062013-102746/. Acesso em: 29/08/2015.

GRYNSZPAN, Mario. Ciência, política e trajetórias sociais: uma sociologia histórica da teoria das elites. Rio de Janeiro: Editora FGV, 1999.

HEINZ, Flávio M. (org.). Por outra história das elites. Rio de Janeiro: Fundação Getúlio Vargas, 2006.

LINHARES, Temístocles. Paraná Vivo: um retrato sem retoques. Curitiba: Imprensa Oficial, 2000.

MAGAlHÃES, Marion Brepohl de. Paraná: Política e Governo. Curitiba: SEED, 2001.

MARTINS, Maria Fernanda. Os tempos de mudança: elites, poder e redes familiares no Brasil, séculos XVIII e XIX. In: FRAGOSO, J.L.R.; ALMEIDA, C.M.C.; SAMPAIO, A.C.J. (org.) Conquistadores e negociantes: Histórias de elites no Antigo Regime nos trópicos. Rio de Janeiro: Civilização Brasileira, 2007.

MARTINS, Romário. Catálogo dos jornaes publicados no Paraná de 1854 - 1907. Curytiba: Typ. e lith. a vapor Impressora Paranaense, 1908. 
História do Paraná. Curitiba: Travessa dos Editores, 1995.

MATTOS, Ilmar Rohloff de. O tempo saquarema. A formação do Estado Imperial. 2a ed., São Paulo: Ed. Hucitec, 1990.

MONTAGNER, Miguel Ângelo. Trajetórias e biografias: notas para uma análise bourdieusiana. Sociologias, Porto Alegre, ano 9, n. ${ }^{\circ} 17$, jan/jun. 2007.

MONTEIRO, Hamilton de Mattos. Da Independência à Vitória da Ordem. In: LINHARES, Maria Yeda (org.). História geral do Brasil. 6 ${ }^{a}$ ed. Rio de Janeiro: Campus, 1990.

NEGRÃO, Francisco. Genealogia Paranaense. Vol.1, Curitiba: Imprensa Paranaense S.A., 1926.

. Genealogia Paranaense. Vol.2, Curitiba: Imprensa Paranaense S.A., 1927.

. Genealogia Paranaense. Vol.3, Curitiba: Imprensa Paranaense S.A., 1928.

. Genealogia Paranaense. Vol.4, Curitiba: Imprensa Paranaense S.A., 1929.

. Genealogia Paranaense. Vol.5, Curitiba: Imprensa Paranaense S.A., 1946.

. Genealogia Paranaense. Vol.6, Curitiba: Imprensa Paranaense S.A., 1950.

OLIVEIRA, Ricardo Costa de. O silêncio dos vencedores. Genealogia, classe dominante e estado do Paraná. Curitiba: Moinho do Verbo, 2001.

. Na teia do nepotismo. Curitiba, PR: Insight, 2012.

RIBEIRO, Darcy. O povo brasileiro: evolução e o sentido do Brasil. $2^{\mathrm{a}}$ ed. $9^{\mathrm{a}}$ reimpressão. São Paulo: Companhia das Letras, 1997. 
RODRIGUES, José Honório. Conciliação e reforma no Brasil. Um desafio histórico-cultural. Rio de Janeiro: Editora Civilização Brasileira S.A., 1965.

Filosofia e história. Rio de Janeiro: Nova Fronteira, 1981.

STECA, Lucinéia \& FLORES, Mariléia. História do Paraná. Do século XVI à década de 1950. Londrina: Ed. UEL, 2002.

STONE, Lawrence. Prosopografia. Revista de Sociologia e Política, Curitiba, Jun 2011, vol.19, $\mathrm{n}^{\mathrm{o}} .39, \mathrm{p} .115-137$.

URUGUAI, Visconde do. Visconde do Uruguai. Ensaio sobre o direito administrativo. Organização e introdução de José Murilo de Carvalho, São Paulo: Ed.34, 2002.

VIANNA, Oliveira. Instituições políticas brasileiras. Primeiro volume. Fundamentos sociais do Estado (Direito público e cultura). São Paulo: José Olympio, 1949.

WACHOWICZ, Ruy Christovam. História do Paraná. 5aedição, Curitiba: Gráfica Vicentina, Ltda, 1982.

WESTPHAlEN, Cecília Maria. O Barão dos Campos Gerais e o comércio de tropas. Curitiba: CD Editora, 1995.

Política paranaense do século XIX. Revista paranaense de desenvolvimento. IPARDES, Curitiba, n.87, jan/abr, 1996, p.51-63. 


\title{
FORCE POLICY OF TRADITIONAL FAMILIES IN PARANÁ (1853-1889)
}

\begin{abstract}
This article discusses the policy in Paraná in the nineteenth century, from emancipation in 1853 to the end of the Brazilian Empire in 1889, using concepts like political class and its relationship to the family institution. Also thinks the same class through the prosopography methodology, focusing on common characteristics of these actors. Indeed, there is a small group, leaders of their large families, who will dominate and organize the Paraná political scene.
\end{abstract}

Keywords: Paraná. Political class. Prosopography. 